\title{
Sistema Nacional de Informações Tóxico-Farmacológicas (Sinitox): 35 anos de resistência
}

\author{
National Poison Information System (Sinitox, in Brazilian acronyn): \\ thirty-five years of resistance
}

\section{Sistema Nacional de Informaciones Tóxico-Farmacológicas (Sinitox): 35 años de resistencia}

\author{
Rosany Bochner | rosany.bochner@icict.fiocruz.br \\ Fundação Oswaldo Cruz (Fiocruz), Instituto de Comunicação e Informação Científica e Tecnológica em Saúde \\ (ICICT), Sistema Nacional de Informações Tóxico-Farmacológicas (Sinitox). Rio de Janeiro, RJ, Brasil.
}

Palavras-chave: Toxicologia; Sistemas de informação em saúde; Envenenamento; Sistemas nacionais de saúde.

Keywords: Toxicology; Health Information Systems; Poisoning; National Health Systems.

Palabras clave: Toxicología; Sistemas de informaciones acerca de la salud; Envenenamiento; Sistemas nacionales de salud.

O Sinitox chega aos seus 35 anos tendo muito o que comemorar. Lança sua nova página na internet e traz como novidade o Banco de Óbitos, que permite ao usuário realizar suas próprias consultas. Os casos também serão disponibilizados de forma a facilitar as pesquisas, em especial a busca pelas séries históricas.

Novas formas de comunicação com a sociedade, mais modernas e dinâmicas, foram pensadas para disponibilizar informações sobre plantas tóxicas e animais peçonhentos, a exemplo dos quizzes comportamentais, que levam o internauta a descobrir com qual agente tóxico se parece. Em breve, estará disponível para a visitação a maquete Casa Educativa, criada para disseminar informações sobre medidas preventivas de intoxicação no ambiente doméstico, mostrando como tornar nossas casas um lugar mais seguro especialmente para as crianças, que são o público mais vulnerável à intoxicação doméstica. Outra importante ação é a campanha "Eu já usei dados do Sinitox", que será lançada nos próximos meses com o propósito de mostrar a relevância do sistema em diversos segmentos da sociedade.

Vale relembrar o contexto histórico do Sistema Nacional de Informações Tóxico-Farmacológicas (Sinitox), coordenado pela Fundação Oswaldo Cruz (Fiocruz), por meio do Instituto de Comunicação e Informação Científica e Tecnológica em Saúde (Icict). Foi criado pelo Ministério da Saúde em agosto de $1980^{1}$, com o objetivo de reunir os dados de intoxicação e envenenamento registrados pelos três Centros de Informação e Assistência Toxicológica existentes na época no país (Centro de Controle de Intoxicações 
de São Paulo, Centro de Informação Toxicológica de Porto Alegre e Serviço de Informação Toxicológica de Belo Horizonte), bem como de proporcionar a implantação de outros centros, em todo o país. Para tal, o Ministério da Saúde alocou recursos por meio de um programa orçamentário específico para a Fiocruz, visando dar suporte financeiro para a implantação desses centros em todos os estados. O repasse de recursos ocorreu via convênios celebrados entre a Fiocruz e as secretarias estaduais e municipais de saúde, ou por meio das Fundações de Saúde vinculadas às secretarias e às universidades públicas.

Com a promulgação da Constituição de 1988, o programa orçamentário do Sinitox foi transferido, a partir de 1989, para a Secretaria Nacional de Vigilância Sanitária, concentrando os repasses de verbas nos órgãos centrais da Administração Federal. Em maio de 1991, com a criação da Coordenação dos Centros de Assistência Toxicológica na Divisão de Avaliação de Riscos, da Secretaria Nacional de Vigilância Sanitária, essa última ficou responsável pela coordenação da Rede de Centros e pela celebração de convênios para repasse de verbas ${ }^{2,3,4}$. Em 1999, com a criação da Agência Nacional de Vigilância Sanitária (Anvisa) ${ }^{5}$, a coordenação dos centros sob a sua responsabilidade foi reafirmada, sendo criada, em 2005, a Rede Nacional de Centros de Informação e Assistência Toxicológica (Renaciat) ${ }^{6}$.

Em que pesem os diversos aspectos políticos, econômicos, sociais e culturais envolvidos na criação dos centros, ao observar a evolução histórica do número dessas instituições implantadas no país, é importante salientar o seu crescimento a partir da criação do Sinitox, em 1980: o número de centros passou de três para seis em apenas um ano e, em 1989, já somavam 22. Foi no mesmo ano da criação do Sinitox que surgiu o primeiro centro apoiado por esse sistema, o Centro de Informação Anti-Veneno da Bahia (Ciave). Infelizmente, tal iniciativa não foi suficiente para manter a continuidade de envio de dados desse centro ao sistema. A partir de 2009, o Ciave deixou de enviar os seus dados ao Sinitox, apesar de fazer parte da Renaciat ${ }^{6}$. Esse comportamento é por demais preocupante, uma vez que as informações que não chegam ao Sinitox também não são disponibilizadas em outros meios, ficando prejudicado o acesso da sociedade e dos gestores tomadores de decisão. Mas isso não ocorre somente no Ciave, muitos outros centros também por diversas razões vêm deixando de cumprir seu papel no que tange ao acesso à informação.

No que se refere à coleta e à disponibilização de dados, a primeira divulgação de resultados estatísticos feita pelo Sinitox ocorreu em 1986, com dados referentes ao ano anterior. A partir daí, o sistema não parou de fornecer publicações anuais, nas quais a participação dos centros, por ser espontânea, variou a cada ano e esteve sujeita a diferentes causas, que vão desde a falta de pessoal para realizar a consolidação dos dados até questões políticas que vão além da gestão do Sinitox, ou mesmo da Fiocruz'. Nos 35 anos de existência do Sinitox, a participação dos centros nas análises estatísticas só alcançou a marca dos 100\% no ano de 1998. No entanto, vem apresentando uma queda importante nos últimos anos, em especial após 2008, quando nove centros se desligaram da Renaciat. Para ilustrar, os resultados estatísticos de 2012 contaram com 20 dos 34 centros em atividade no país (58,8\% de participação) e, apesar de estarmos em março de 2016, somente neste mês os dados estatísticos de 2013 serão lançados com a participação de 14 centros, ou seja, de menos de $42 \%$.

Em contrapartida, em 2015, foi publicada a Portaria GM n ${ }^{\circ} 1.678$ que institui os Centros de Informação e Assistência Toxicológica (CIATox) como estabelecimentos de saúde integrantes da Linha de Cuidado ao Trauma, da Rede de Atenção às Urgências e Emergências no âmbito do SUS ${ }^{8}$. Com base nessa portaria, os centros vão receber incentivo financeiro de $\mathrm{R} \$ 10.000,00$ (dez mil reais) por mês como forma de apoio à manutenção de suas atividades. Segundo essa portaria, considera-se que uma das atividades essenciais dos CIATox é a notificação de eventos para a saúde pública, com destaque para intoxicações agudas e crônicas. No entanto, a disponibilização pública desses dados não foi mencionada na portaria.

Ao longo da trajetória do Sinitox, além das dificuldades de manutenção das análises estatísticas, o sistema vem resistindo de inúmeras maneiras, como na manutenção de projetos bem-sucedidos que foram 
descontinuados por diversos motivos, a exemplo da revista Brincando e aprendendo e do livro Jardim das plantas tóxicas.

Espera-se que nas próximas décadas o Sinitox se fortaleça ainda mais e siga revigorado em direção à missão de compilar e divulgar dados essenciais para a consolidação da saúde pública brasileira.

\section{Referências}

1. Brasil. Ministério da Saúde.Implantação da Coordenação do Sistema Nacional de Informações TóxicoFarmacológicas, Assinado em 7 agosto de 1980, Brasília: Diário Oficial da União, (02 setembro 1980). Disponível em: http://sinitox.icict.fiocruz.br/sites/sinitox.icict.fiocruz.br/files/Extrato\%20de\%20 contrato\%20entre\%20Fiocruz $\% 2$ C $\% 20$ MS $\% 20$ e $\% 20$ Secretaria $\% 20$ de $\% 20$ Sa $\%$ C3\%BAde $\% 20$ do $\% 20$ Rio\%20Grande\%20do\%20Sul.pdf. Acesso em: 19 fev 2016.

2. Bortoletto ME. Tóxicos, Civilização e Saúde: contribuição à análise dos sistemas deinformações tóxicofarmacológicas no Brasil. Rio de Janeiro: Fundação Oswaldo Cruz; 1993.

3. Fundação Oswaldo Cruz. Centro de Informação Científica e Tecnológica. Sinitox - Sistema Nacional de Informações Tóxico-Farmacológicas. Diretório - Centros de Assistência Toxicológica. Rio de Janeiro: Sinitox/Icict/Fiocruz; 1994.

4. Fundação Oswaldo Cruz. Centro de Informação Científica e Tecnológica.Sinitox - Sistema Nacional de Informações Tóxico-Farmacológicas. Diretório - Centros de Assistência Toxicológica. Brasil, 1996. Rio de Janeiro: Sinitox/Icict/Fiocruz; 1996.

5. Brasil. Lei n. 9.782, de 26 de janeiro de 1999. Define o Sistema Nacional de Vigilância Sanitária, cria a Agência Nacional de Vigilância Sanitária, e dá outras providências. Brasília: Diário Oficial da União (27 jan.1999).

6. Anvisa. Diretoria Colegiada.Criação da Rede Nacional de Centros de Informação e Assistência Toxicológica (Renaciat), Resolução RDC no 19(3 de fevereiro de 2005), Brasília (DF): Diário Oficial da União, p. 39-41.

7. Bochner R. Informação sobre intoxicações e envenenamentos para a gestão do SUS: um panorama do Sistema Nacional de Informações Tóxico-Farmacológicas - Sinitox. Reciis; 2013; 7(2) Disponível em: http://www.reciis.icict.fiocruz.br/index.php/reciis/article/view/472/1123. Acesso em: 19 fev 2016.

8. Brasil. Ministério da Saúde. Institui os Centros de Informação e Assistência Toxicológica (CIATox) como estabelecimentos de saúde integrantes da Linha de Cuidado ao Trauma, da Rede de Atenção as Urgências e Emergências no âmbito do SUS, Portaria no 1.678, Brasília: Diário Oficial da União, (2 outubro 2015). Disponível em: http://portalsaude.saude.gov.br/images/pdf/2015/outubro/14/CIAToxPortaria-MS-1678-2015.pdf. Acesso em: 16 fev 2016. 